\title{
A CASE FOR DIAGNOSIS WITH A NOTE ON INFANTILE CORTICAL HYPEROSTOSIS (CAFFEY'S SYNDROME)*
}

\section{BY}

\author{
E. M. C. DUNLOP
}

\section{From the Whitechapel Clinic, London}

Syphilitic periostitis in the infant has become less common than was formerly the case. In recent years it has been recognized that the radiological appearances of syphilitic periostitis can be closely simulated by other conditions, including

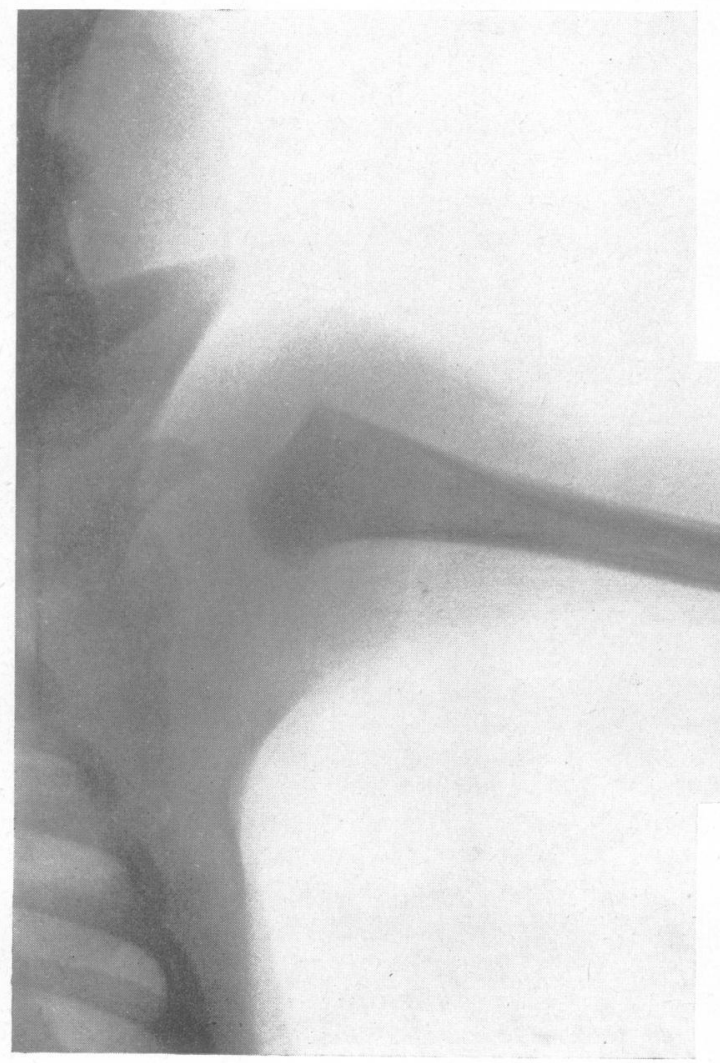

FIG. 1.- $X$-ray photograph of humerus, September 12, 1949 , showing periosteal reaction at 8 weeks. that described by Caffey and Silverman (1945), and named by them "infantile cortical hyperostosis".

\section{Case Report}

A male infant was brought to the Whitechapel Clinic by his foster mother on August 30, 1949, when he was nearly 7 weeks old. She was worried because she had heard that his mother had "venereal disease ". She said the baby was thriving but had recently suffered from diarrhoea.

Examination.-He was an apparently healthy baby weighing $9 \mathrm{lb} .10 \mathrm{oz}$. There were some shallow perianal excoriations extending to the anal margin, but these appeared to be non-syphilitic and darkfield examination was negative. The Wassermann reaction and Price's precipitation test were negative in the blood serum.

September 12, 1949. - The baby's feeding régime had been altered; the diarrhoea hadceased and the ulceration had healed.

Routine $x$ rays of the long bones were taken, and the report ran as follows:

There is a periosteal reaction in the outer aspects of both femora, the medial aspects of both tibiae, and also at the humeri. There is no evidence of epiphysitis or osteitis. The periostitis should certainly be due to specific disease (Figs 1 and 2).

Maternal History.-Meanwhile the mother's records (see Fig. 3) had been traced at the Royal Northern and Sheffield Street Hospitals. She was * Received for publication October 29, 1951. 
FIG. 2. $-X$-ray photograph of legs, September 12,1949 , showing periosteal reaction at 8 weeks. 


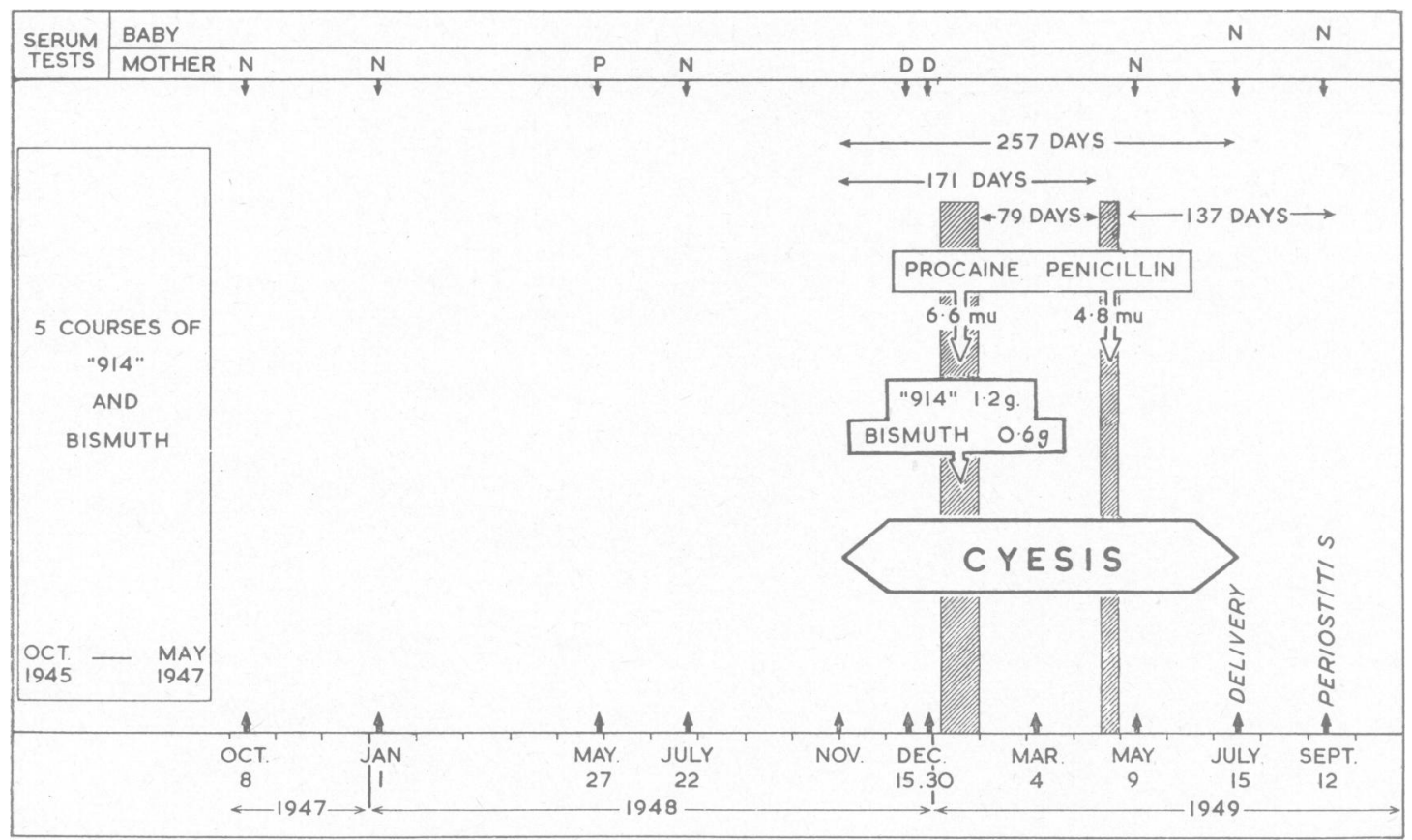

$\mathrm{N}=$ negative $; \mathrm{D}=$ doubtful $; \mathrm{P}=$ positive $; \mathrm{mu}=$ mega units.

FIG 3.-Treatment of mother and results of successive serum tests in mother and baby

unmarried at the time of enquiry and 23 years of age. Between October, 1945, and May, 1947, she had been treated with five courses of ' 914 ' and bismuth in a corrective training institution. Precise details of her treatment were not available. The blood Wassermann reaction had been "strongly positive" initially, but was negative by May, 1947. She then attended another hospital where the blood Wassermann reaction was negative on October 8 , 1947, and January 1, 1948.

On May 27, 1948, the blood Wassermann reaction (WR) was positive. A further specimen tested at the Medical Research Council Laboratory gave the following result :

Quantitative Wassermann reaction $\because 4$. Positive 1 in 20 dilution.

Price precipitation reaction (P.P.R.) $\quad . \quad 0$ units.

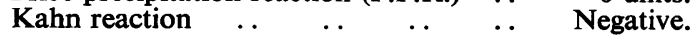

These suggested that the reaction might be a biological false positive. On July 22 , the blood WR was negative and a further specimen, examined at the Medical Research Council Laboratory, gave negative results with the WR, P.P.R., and Kahn test.

On December 15 and 30, the blood WR was reported as "doubtful". Examination on the latter date showed her to be about 2 months pregnant. She was given 600,000 units of procaine penicillin by intramuscular injection on January 5 ; this injection was repeated each day (except January 11) until January 16-a total dosage of $6,600,000$ units. On January 18 she was given arsphenamine diglucoside $0.3 \mathrm{~g}$. intravenously and bismuth $0.2 \mathrm{~g}$. intramuscularly. On January 24 and 31 she was given $0.45 \mathrm{~g}$. arsphenamine diglucoside and $0.2 \mathrm{~g}$. bismuth. She then defaulted.

On March 4 the patient attended again and was given $0.45 \mathrm{~g}$. arsphenamine diglucoside and $0.2 \mathrm{~g}$. bismuth.

She then defaulted until April 20 when she was started on a course of procaine penicillin, 600,000 units daily for 8 days to a total of 4,800,000 units.

The blood WR was negative on May 9 and on July 15 the patient gave birth to an apparently fullterm male child. The. WR of the cord blood was negative and that of the uterine blood was reported as "doubtful". The Kahn test was negative in both specimens.

On July 25 the patient left hospital and subsequently refused any further tests or examination. Information about her son, and interviews at this and at another hospital, did nothing to change her attitude. 


\section{Discussion}

It is clear that the periostitis could be a manifestation of active syphilis, or a residuum of the disease, or of non-specific origin. The treatment with penicillin late in pregnancy and the baby's negative blood WR made an active lesion less likely, as did the fact that there was no clinical and no other radiological evidence suggesting syphilis.

Between January 31 and April 20 the patient had been living in a house of ill repute, and during this time she had received only one injection of arsenic and one of bismuth. Relapse during this period, or re-infection in the earlier part of it, could have caused foetal periostitis. The penicillin in April could then have cured the maternal and foetal syphilis, leaving the residual but healing periostitis to show on $x$-ray examination 5 months later. The time intervals are such as to make this an unlikely but possible explanation. The absence of osteochondritis, which usually accompanies an actively progressing syphilitic periostitis at this early stage, is a point in favour of a non-specific cause ; spontaneous regression may leave periostitis as a bone change in untreated syphilis but this is not common at the age of 8 weeks.

There was no positive evidence to suggest that the periostitis was of non-specific origin. There was a history of diarrhoea at the first attendance, but this had been transient, lasting less than a week ; the baby was well nourished and there was no evidence to suggest vitamin $\mathrm{C}$ deficiency as a cause.

" Periostitis" due to excessive intake of vitamin $A$ is unknown in a child of this age, for the overdosage required is very great and must be prolonged for at least 6 months (Caffey, 1950).

Extensive callus formation, without evidence of fracture, has been described in patients with osteogenesis imperfecta ; Brailsford (1943) ascribed such changes to coincident scurvy. Fairbank and Baker (1948) described seven similar cases but considered that scurvy played no part in the condition. The clinical picture which they described and the shadows of exuberant callus found on $x$-ray examination of their patients appear quite distinct from those of the patient under review.

Hospital records show that the child was mildly jaundiced 3 days after birth, but the condition had cleared by the tenth day of life. This was, in any case, the mother's first pregnancy and the baby was otherwise healthy. In retrospect, the jaundice would appear to have been physiological and could not be correlated with the gross generalized periosteal change discovered later.

The rapid growth of a premature infant may give rise to the appearance of "periostitis" on $x$-ray examination. The estimate that pregnancy was 2 months advanced at the end of December suggests that this was a 37-week pregnancy. There was no other clinical evidence of prematurity and the birthweight was $6 \mathrm{lb} .6 \mathrm{oz}$.

In view of this evidence and of the considerable changes present on $x$-ray examination, prematurity appeared a most unlikely cause.

It has been suggested that the diagnosis was one of infantile cortical hyperostosis.

Infantile Cortical Hyperostosis (Caffey's Syndrome).-Caffey and Silverman (1945) described a clinical syndrome to which they gave the name " infantile cortical hyperostosis". Since that time the condition has been recognized in infants of many races. An analysis of 42 case reports which have appeared in the literature gives the following picture. The disease is one of early infancy, 80 per cent. of cases having been recognized within the first 4 months of life : Berkheiser (1949) has reported a case where the condition dated from birth ; Smyth, Potter, and Silverman (1946) report another where the onset occurred as late as 21 months of age, but Caffey (1950) has expressed the belief that the condition in older infants is a separate entity resulting from excessive intake of vitamin A.

Sex.-The condition has been found more often in males than females; study of the literature shows 28 case reports of male children to only fourteen females.

General Health.-The affected infants were in most cases apparently healthy, although upper respiratory tract infections had been associated in ten patients (24 per cent.).

Soft Tissue Swelling.--In most cases a swelling developed suddenly over a bone, usually the lower jaw or a limb : mandibular swelling occurred in 25 cases (60 per cent.) giving rise to a characteristic " heavy" facies, and limbs were swollen in 26 (63 per cent.); in only one patient out of the $\mathbf{4 2}$ reviewed was there no swelling at either of these sites. This patient was aged 19 months and was later thought by Caffey (1950) to have suffered from a different syndrome due to an excessive intake of vitamin A. Swellings occurred less often at other sites, one or both clavicles being affected in six patients and the scapula in two, while in single cases the ribs, pelvis, and parietal and occipital bones were affected. The swellings were usually tender, deep-seated, firm, and poorly outlined ; they showed no increased warmth to the touch nor redness of the overlying skin. Pain or irritability occurred in 36 patients and was often severe ; in only four patients were the swellings found to be painless.

$X$-Ray Appearances.-Examination showed external thickening of the corticalis; this underlay the soft tissue swellings and, in nearly all cases, was found to affect clinically normal bones as well. There was involvement of long bones of the extremities in 31 out of 
41 patients, two or more limbs being affected in 27 of these. Eight of the ten patients without radiological abnormalities in the bones of the limbs had mandibular swellings with underlying bone change, one had mandibular cortical hyperostosis without overlying swelling, and the remaining patient had mandibular swelling without radiological change. Altogether 25 patients showed mandibular cortical hyperostosis; Case 7 of Smyth, Potter, and Silverman (1946) has already been noted as having periostitis of the long bones without overlying swellings and with onset at a later age. The patient described by Thompson (1949) was excluded from this analysis because no details were given of the findings on $x$-ray examination. The cortical thickening was quite often gross and irregular but frequently appeared as a thin periosteal veil ; it was more marked over the central than the terminal segments of the shaft and was sometimes lamellated. There were no other associated bone changes. Serial $x$-ray examination often showed successive layers of bone at the affected sites, and the medullary cavity was sometimes enlarged, so that, before the normal architecture was restored, the bone might appear large and osteoporotic. O'Reilly (1949) described such bones as appearing older than their chronological age. Van Zeben (1948) described marked tibial curvature in three patients ; the only one with unilateral tibial curvature appeared normal 7 years after the onset of disease, the second died after mastoiditis, insufficient time had elapsed for the follow up of the third. Unilateral anterior tibial bowing was present one year after the onset of disease in the case described by Smitham and Palmer (1950).

Pleural Effusion.-There was evidence of pleural effusion in 3 patients and of pleural thickening in 2 . In only one of these five patients were the ribs not involved by periosteal change.

Fever.-In 33 out of the 37 patients in whom the temperature was recorded fever was present. It varied from very moderate levels to that of $105^{\circ} \mathrm{F}$. in one case recorded by Burke (1948).

Blood.-Secondary anaemia was present in 28 out of 33 patients and in ten it was severe enough to merit transfusion on one occasion or more. Leucocytosis was an infrequent finding when allowance was made for the normal high white cell count and lymphocytosis of infancy; when it occurred it was not characteristic. The blood sedimentation rate was raised in a few patients, but it was not recorded in the majority.

Serum.-37 patients had negative serological tests for syphilis (S.T.S.). There was no record of such tests in the remaining five, but it was noted that the parents of one had negative S.T.S. The patient described by Smitham and Palmer (1950) was treated for syphilis despite negative S.T.S. in both the baby and the parents, but the diagnosis of infantile cortical hyperostosis was made subsequently. The cerebrospinal fluid (C.S.F.) was found to be normal in six of the seven cases examined. Shuman (1948) found nine cells (consisting of 5 lymphocytes and 4 polymorphonuclear leucocytes) per cu. $\mathrm{mm}$. C.S.F., in his patient with negative S.T.S.
Biopsy.-In twelve patients examined the characteristic finding was that of new cancellous bone with great increase of osteoblasts. Caffey (1939) pointed out that this picture resembles that of syphilis, but quoted McLean in saying that it is extremely doubtful whether an unequivocal microscopic diagnosis of syphilitic periostitis can be made. Gland biopsies showed no abnormality (O'Reilly, 1949 ; Smyth, Potter, and Silverman, 1946). Invasion of muscle by inflammatory cells was noted by Dickson, Luckey, and Logan (1947) and by Kane and Borzell (1947).

Clinical Course.-The course of the disease varied considerably and recrudescence of clinical symptoms or spread of radiological changes occurred on one or more occasions in thirty patients. Clinical signs may persist for months and $x$-ray changes for much longer. The febrile period was short in many patients but lasted over 4 months in one, and 6 months in another.

Autopsy.-Two patients died suddenly. The boy described by Mossberger (1950) developed painful swellings of the right arm and generalized glandular enlargement at 4 months of age. He was discharged from hospital apparently improved, but at 8 months of age he was found dead in bed and autopsy showed generalized hyperplasia of all lymphoid tissue including the thymus ; focal enteritis and local glandular enlargement were present suggesting the lesions of typhoid fever. Cancellous bone was deposited round the humeral diaphysis to a thickness of $3 \mathrm{~mm}$. Microscopy showed cancellous bone with increase of osteoblasts ; no treponemata were seen in sections stained by Levaditi's method. The second patient described by Van Zeben (1948) died 3 weeks after admission and death was attributed to nutritional disturbance following mastoiditis. It is notable that O'Reilly (1949) also found generalized glandular enlargement in the patient he described. Smyth, Potter, and Silverman (1946) commented on enlargement of the thymus as shown by $x$-ray examination in two of their patients.

In considering the clinical differentiation of this condition from syphilis, two further points are of interest ; namely, that frankly muco-purulent nasal discharge may occur, and that enlargement of the liver and spleen has also been recorded, but only as an exceptional finding.

Summary of the cardinal features of infantile cortical hyperostosis shows that there were soft tissue swellings in 41 out of 42 patients, mandibular cortical hyperostosis in 61 per cent., pain or irritability in 90 per cent, fever in 90 per cent., anaemia in 85 per cent., and clinical recurrence or radiological extension in 71 per cent. The patient under review showed none of these features, although the bone changes on $x$-ray examination were identical with those of infantile cortical hyperostosis.

Caffey and Silverman (1945) pointed out that only the tender and largest lesions were clinically evident, while most of the bony changes were 
unsuspected until found on $x$-ray examination. For this reason they concluded that many mild cases would not have been recognized. The cause of infantile cortical hyperostosis is unknown and the variety of the published cases suggests that more than one factor may be responsible.

It is therefore possible that the findings on routine $x$-ray examination in this infant were due to infantile cortical hyperostosis or to an allied condition.

\section{Conclusion}

It seemed that the differential diagnosis lay between syphilitic periostitis, either active or residual, and non-specific periosteal reaction, possibly of the kind described by Caffey as infantile cortical hyperostosis.

In view of the maternal history it was not possible to exclude syphilis, although if the changes were syphilitic they might well have been residual and not due to active disease. In view of the doubt that existed it was decided that the right and proper course was to give antisyphilitic treatment. Accordingly on September 19 the baby was admitted to hospital and given procaine penicillin 150,000 units daily for 10 days.

Further Progress.-The child has been examined clinically and serologically at frequent intervals. At the age of 19 months he appears well and active ; there are no syphilitic stigmata but he is a little backward in talking. Serological tests have remained negative.

$X$-Ray Report (March 4, 1950).-There is quite an appreciable change since the films of September, 1949. The periosteal reaction on the shafts of the long bones is not now obvious, though there is some thickening of the cortex.

$X$-Ray Report (July 15, 1950).-The bones now appear normal.

\section{Summary}

The case of an infant with generalized periostitic change is presented for diagnosis. The differential diagnosis is considered and the condition known as infantile cortical hyperostosis (Caffey's Syndrome) is reviewed.
I wish to thank Dr. Elizabeth Keighley and Dr. Millicent Hamilton-Johnstone for information about the mother's condition and treatment when she was under their care, Mr. R. F. Ruddick of the Photographic Dept., London Hospital, for the $x$-ray photographs, and Mr. A. J. King for his help and advice and for permission to publish this case.

\section{REFERENCES}

Berkheiser, E. J. (1949). Proc. Inst. Med. Chicago, 17, 308.

Brailsford, J. F. (1943). Brit. J. Radiol., 16, 129.

Burke, F. G. (1948). J. Pediat., 32, 441.

Caffey, J. (1939). Amer. J. Roentgenol., 42, 637.

- (1946). J. Pediat., 29, 541.

(1950). Pediatrics, Springfield, 5, 672.

, and Silverman, W. A. (1945). Amer. J. Roentgenol., 54, 1.

Dickson, D. D., Luckey, C. A., and Logan, N. H. (1947). J. Bone Jt. Surg., 29, 224.

Fairbank, H. A. T., and Baker, S. L. (1948). Brit. J. Surg., 36, 1.

Kane, S. H., and Borzell, F. F. (1947). Amer. J. Roentgenol., 58, 629.

Mossberger, J. I. (1950). Amer. J. Dis. Child., 80, 610. O'Reilly, J. N. (1949). Arch. Dis. Childh., 24, 67.

Shuman, H. H. (1948). J. Pediat., 32, 195.

Smitham, J. H., and Palmer, P. (1950). Brit. J. Radiol., 23, 162

Smyth, F. S., Potter, A., and Silverman, W. (1946). Amer. J. Dis. Child., 71, 333.

Thompson, C. G. (1949). Conn. med. J., (1949). 13, 28.

Van Zeben, W. (1948). Acta paediatr., Stockh., 35, 10.

CASES REPORTED BY THE FOLLOWING AUTHORS ARE INCLUDED IN THE ANALYSIS OF CAFFEY'S SYNDROME BUT ARE NOT ACKNOWLEDGED INDIVIDUALLY IN THE TEXT.

Astley, R. (1950). Brit. J. Radiol., 23, 675.

Bauman, C. S., and Lubell, M. F. (1949). J. Maine med. Ass., 40, 5.

Bradlow, P. A., and Steinberg, S. H. (1950). J. Bone Jt. Surg., 32a, 677.

Chen, K. T., and Yu, T. S. (1948). Chin. med. J., 66, 266. Delano, P. J., and Butler, C. D. (1947). Amer. J. Roentgenol., 58, 633.

Ellis, R. W. B. (1939). Proc. roy. Soc. Med., 32, 139.

Fisk, C. (1947). J. Iowa med Soc., 37, 529.

Gipson, A. C., and Clark, B. P. (1948). Pediatrics, Spring field, 1, 221.

MacGregor, M., and Davies, R. (1949). Lancet, 2, 1176.

Ross, S. (1948). J. Pediat., 32, 445.

Sakula, J. (1950). Proc. roy. Soc. Med., 43, 242.

Sherman, M. S. (1949). Proc. Inst. Med. Chicago, $17,307$.

Whipple R. K. (1947). New Engl. J. Med., 236, 239. 